\title{
Injury to the eye by the sap of Euphorbia royleana
}

\author{
G. C. SOOD, B. K. SOFAT, AND R. D. CHANDEL \\ From the Department of Ophthalmology, H. P. Medical College, Simla, India
}

The saps of some plants are known to be highly irritant to the eye. We have recently seen a patient in whom accidental splashing with the sap of Euphorbia royleana caused acute bilateral conjunctivitis with corneal ulceration and iridocyclitis. Euphorbia royleana (Churee) is used as a hedge in some parts of India to protect crops from predatory or stray animals. It is a glabrous fleshy shrub of cactus-like aspect, and is common on hills below 6,ooo ft. in the Western Himalayas (Figs I and 2). The thick white milky sap contains alkaloids (Collett, I902).

\section{Case report}

A man aged ${ }_{3} 6$ years came to the H.P. Medical College Hospital, on February 24, I97 I, with acute pain and soreness of the eyes. He had been cutting branches of the shrub 6 days previously with the object of planting them around a field, when the sap splashed into his eyes. He felt excruciatingo

(I)

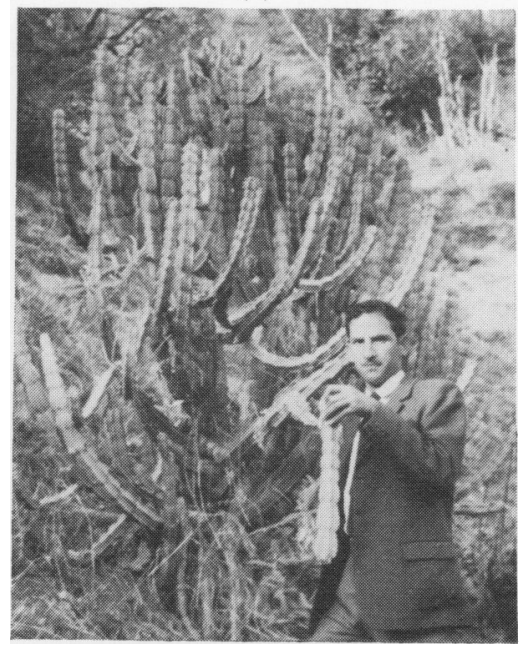

FIG. I The shrub Euphorbia royleana compared with the height of a normal man

FIG. 2 A branch of the shrub

(2)

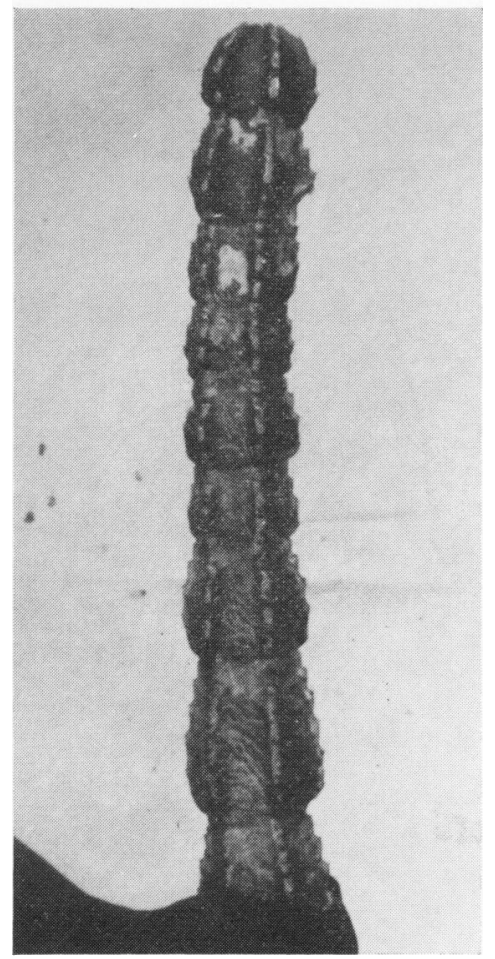


pain and watering from the eyes and almost complete loss of vision with swelling of the lids. He had no treatment for 24 hours, but then the juice of another plant locally called Nanhuan (Sedum multicaule) was instilled into the eyes and gave slight relief. As the pain persisted and vision was seriously impaired he came to the hospital, but not until 6 days after the accident.

\section{EXAMINATION}

He was a slim healthy man with normal pulse and respiration. The eyes showed marked photophobia, swollen lids, and chemosed conjunctivae. The corneae were hazy and oedematous and in places ulcerated. The anterior chamber, iris, pupil, lens, and posterior segment could not be seen. The visual acuity was reduced to perception of light.

The patient was admitted to hospital and treated with saline irrigations, atropine I per cent., and terramycin eye ointment three times a day, and later with corticosteroid eyedrops. His condition steadily improved and the chemosis regressed.

On March 19, 197I, the chemosis had completely subsided but there was still marked congestion. The corneal ulcers had healed leaving superficial corneal opacities. The pupils were semidilated and irregular with multiple posterior synechiae. The visual acuity was $4 / 60$ in the right eye and $2 / 60$ in the left.

\section{Discussion}

The sap of plants of the Euphorbiaceae family are known to cause vesicant dermatitis and chemotic conjunctivitis with keratitis. According to Duke-Elder (1954), Snow and Harley (1944) described ocular complications caused by the sap of the apple beech, and the irritant is believed to be Urushiol or a related compound (Merrill, 1944). Ocular reaction has been reported from the saps of other members of the same family-Tithymalus cyparissias (Hilbert, I897), Euphorbia antiquorum (Santos Fernandez, I892), and Tithymalus esula (Lewin and Guillery, I913).

In our case the sap of Euphorbia royleana produced intense conjunctival, corneal and iritic inflammatory reaction, but no dermatitis. The acute reaction may have been due to the greater penetration of the sap alkaloids through the cornea.

\section{Summary}

A case is reported of ocular injury resulting from the sap of Euphorbia royleana.

\section{References}

COLlett, H. (I902) "Flora Simlensis", p. 446. Thacker, London DUKE-ELDER, s. (1954) “Text-book of Ophthalmology”, vol. 6, p. 675 I. Kimpton, London HILBERT, R. (1897) Zbl. prakt. Augenheilk., 21, 53 (Cited by Duke-Elder, 1954)

LEWin, L., and GUillery, H. (1913) "Die Wirkungen von Arzneimitteln und Giften auf das Auge", 2nd ed., ii, p. 70 I. Hirschwald, Berlin (Cited by Duke-Elder, 1954)

Merrill, E. D. (1944) J. Amer. med. Ass., 124, 222 (Cited by Duke-Elder, 1954)

Santos Fernandez (1892) Cron. Med.-quir. Habana, 18, 73, 145, 22 I (Cited by Duke-Elder, 1954)

snow, J. S., and harley, R. D. (1944) Arch. Derm. Syph. (Chicago), 49, 236 (Cited by Duke-Elder, 1954) 